\title{
CRRT during TAE in Unstable Pelvic Fracture with Severe Lactic Acidosis
}

\author{
Chan Yong Park', Hyun Min Cho², Hoon Kwon³, Chang Ho Jeon ${ }^{3}$, Chang Won Kim \\ ${ }^{1}$ Department of Trauma Surgery, Wonkwang University Hospital, Iksan, Korea \\ ${ }^{2}$ Department of Trauma Surgery, Pusan National University Hospital, Busan, Korea \\ ${ }^{3}$ Department of Radiology, Pusan National University Hospital, Busan, Korea
}

Here, we report a case of continuous renal replacement therapy (CRRT) operation immediately before starting transcatheter arterial embolization (TAE) in a patient with severe lactic acidosis after blunt trauma. A 60-year-old male presented to the emergency department of our hospital at midnight after falling from a height of $9 \mathrm{~m}$. His initial systolic blood pressure was $70 \mathrm{~mm} \mathrm{Hg}$, and initial arterial blood gas analysis (ABGA) revealed a pH of 6.99 and lactic acid profile of $13.5 \mathrm{mmol} / \mathrm{L}$. Abdominal CT revealed an unstable pelvic ring fracture. The CRRT was primed before TAE. A catheter was inserted in the intervention room, and CRRT was operated during TAE. The patient's vital signs improved immediately after the TAE. His ABGA revealed a pH of 7.18, and his lactic acid profile was $7.2 \mathrm{mmol} / \mathrm{L}$. In addition, ABGA at $6 \mathrm{~h}$ after TAE showed improvement, with a pH of 7.38 and lactic acid profile of $7.2 \mathrm{mmol} / \mathrm{L}$. The CRRT was applied only on day 1 . On the same day, an iliosacral screw was fixed. After 4 weeks of admission, the patient was transferred to a rehabilitation hospital without any specific complications.

(Trauma Image Proced 2018(1):20-22)

Key Words: Renal replacement therapy; Therapeutic embolization; Lactic acidosis; Blunt injury; Pelvic bones

\section{CASE}

A 60-year-old male presented to the emergency department at midnight through referral by another hospital, where he underwent transcatheter arterial embolization (TAE) for pelvic bleeding that developed after falling from a height of $9 \mathrm{~m}$. The patient's vital signs were as follows: systolic blood pressure, $70 \mathrm{~mm}$ $\mathrm{Hg}$; pulse rate, 128 beats/min; respiration rate, 40 breaths $/$ min; body temperature, $36.3^{\circ} \mathrm{C}$; and oxygen saturation, $89 \%$. Accordingly, immediate intubation and mechanical ventilation were performed. His initial arterial blood gas analysis (ABGA) revealed a $\mathrm{pH}$ of $6.99, \mathrm{HCO}_{3}{ }^{-}$of 10.8 , lactic acid profile of 13.5 $\mathrm{mmol} / \mathrm{L}$, and a base excess of -19.6 . Abdominal CT after fluid resuscitation demonstrated an unstable pelvic ring fracture (Fig. 1.). The patient was therefore suspected of hemorrhagic shock caused by persistent bleeding from the blood vessels in the pelvis. Therefore, we decided to perform TAE for hemorrhage control. Priming of the continuous renal replacement therapy (CRRT) was conducted during the interventional radiologist's visit to the hospital. A catheter was inserted via the left femoral vein in the intervention room immediately before

Received: February 27, 2018 Revised: March 5, 2018 Accepted: May 13, 2018

Correspondence to: Chan Yong Park, Department of Trauma Surgery, Wonkwang University Hospital, 895, Muwang-ro, Iksan, Jeonbuk 54538, Korea

Tel: 82-63-859-2602, Fax: 82-63-859-2029, E-mail: wkafyddl@hanmail.net

Copyright (c) 2018 Korean Association for Research, Procedures and Education on Trauma. All rights reserved.

@) This is an open-access article distributed under the terms of the Creative Commons Attribution Non-Commercial License (http://creativecommons.org/ licenses/by-nc/4.0) which permits unrestricted noncommercial use, distribution, and reproduction in any medium, provided the original work is properly cited 


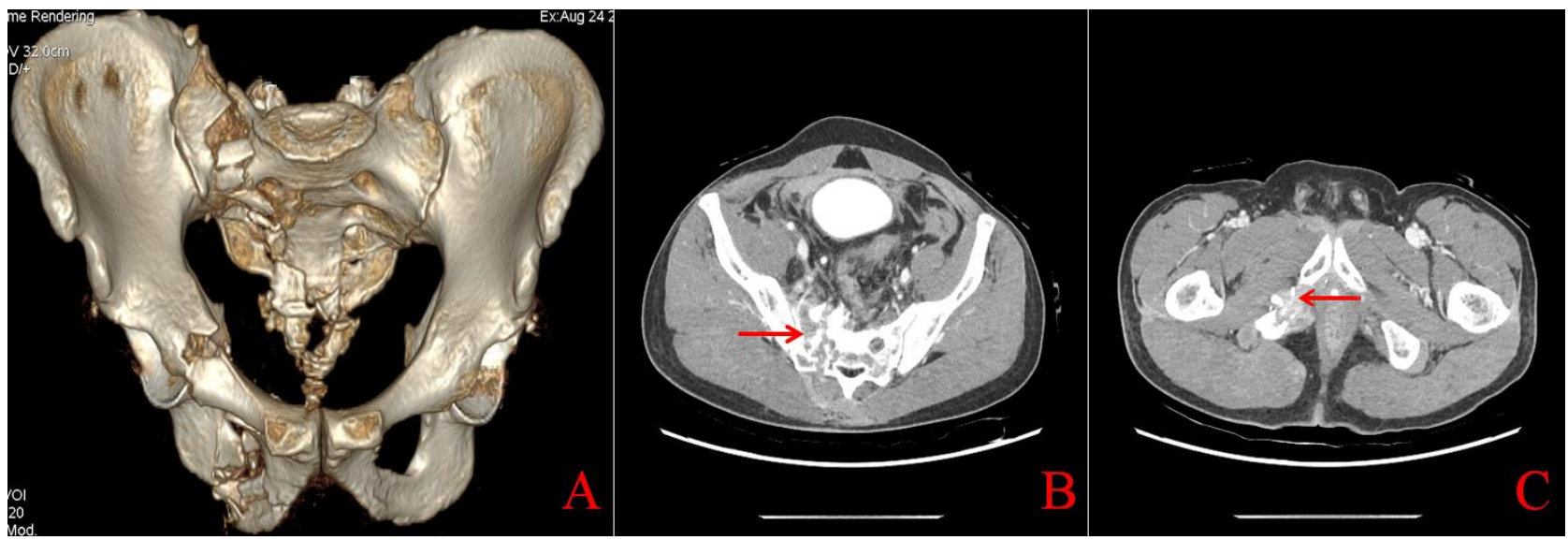

Fig. 1. (A) Abdominal CT after fluid resuscitation demonstrating an unstable pelvic ring fracture

(B) The bleeding foci are suspected to be around the separated right sacroiliac joint and (C) the fractured right ramus

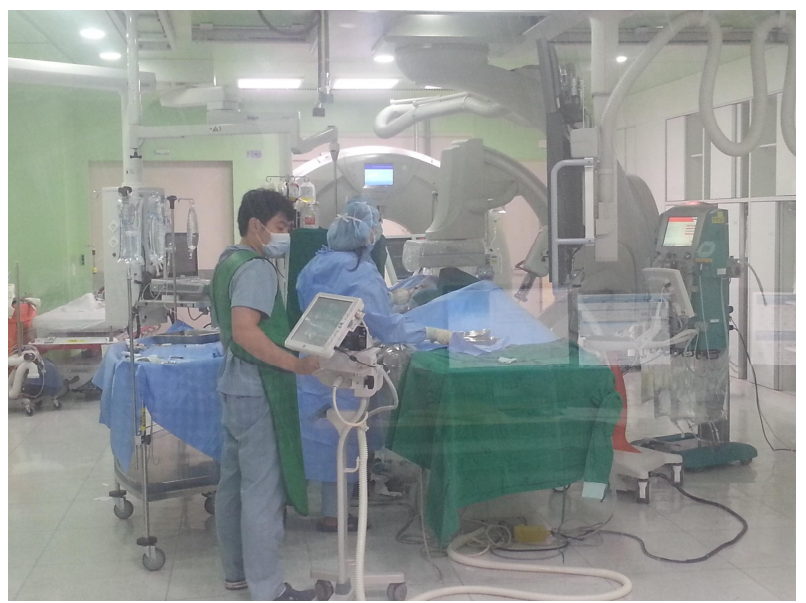

Fig. 2. A catheter inserted via the left femoral vein in an intervention room immediately before angiography, and CRRT performed during TAE

angiography, and CRRT was performed during TAE (Fig. 2.). In the subsequent angiography, bleeding was observed in the right iliolumbar and both the internal pudendal arteries, and embolization was performed (Fig. 3.). Treatment, including CRRT, was performed in the trauma intensive care unit after TAE.

Vital signs observed immediately after the TAE were as follows: blood pressure, $135 / 79 \mathrm{~mm} \mathrm{Hg}$; pulse rate, 135 beats/min; and body temperature, $36.5^{\circ} \mathrm{C}$. In addition, ABGA revealed a $\mathrm{pH}$ of $7.18, \mathrm{HCO}_{3}{ }^{-}$of 10.8 , lactic acid profile of $7.2 \mathrm{mmol} / \mathrm{L}$, and a base excess of -11.3. Moreover, his vital signs at $6 \mathrm{~h}$ after the TAE were more stable, as follows: blood pressure, 124/57 $\mathrm{mm} \mathrm{Hg}$; pulse rate, 77 beats/min; and body temperature, $37.0^{\circ} \mathrm{C}$. Furthermore, his ABGA revealed a $\mathrm{pH}$ of 7.38 , $\mathrm{HCO}_{3}{ }^{-}$of 22.5 , lactic acid profile of $7.2 \mathrm{mmol} / \mathrm{L}$, and a base excess of -1.0 . (Table 1.). CRRT was applied only on day 1 . On the same day, an iliosacral screw was fixed. After 4 weeks of admission, the patient was transferred to a rehabilitation hospital without any specific complications.

\section{DISCUSSION}

Lactic acidosis is associated with high morbidity and mortality. Its treatment involves correction of the underlying causes of the disease and optimizing adequate oxygen delivery to the affected tissues (1). CRRT is a renal replacement therapy intended to be continuously applied for $24 \mathrm{~h}$ in an ICU set-up (2).

If TAE is required to stop bleeding in a patient with severe lactic acidosis, CRRT operation during TAE is one of the factors that can improve acidosis. However, it is also important to not waste considerable time in operating CRRT in an intervention room. Therefore, we suggest priming the CRRT before the interventional radiologist's visit to the hospital.

Recently, there have been reports on the application of early CRRT in patients with acute kidney injury (3-5). However, it is extremely difficult to identify an early CRRT in patients with severe lactic acidosis, 


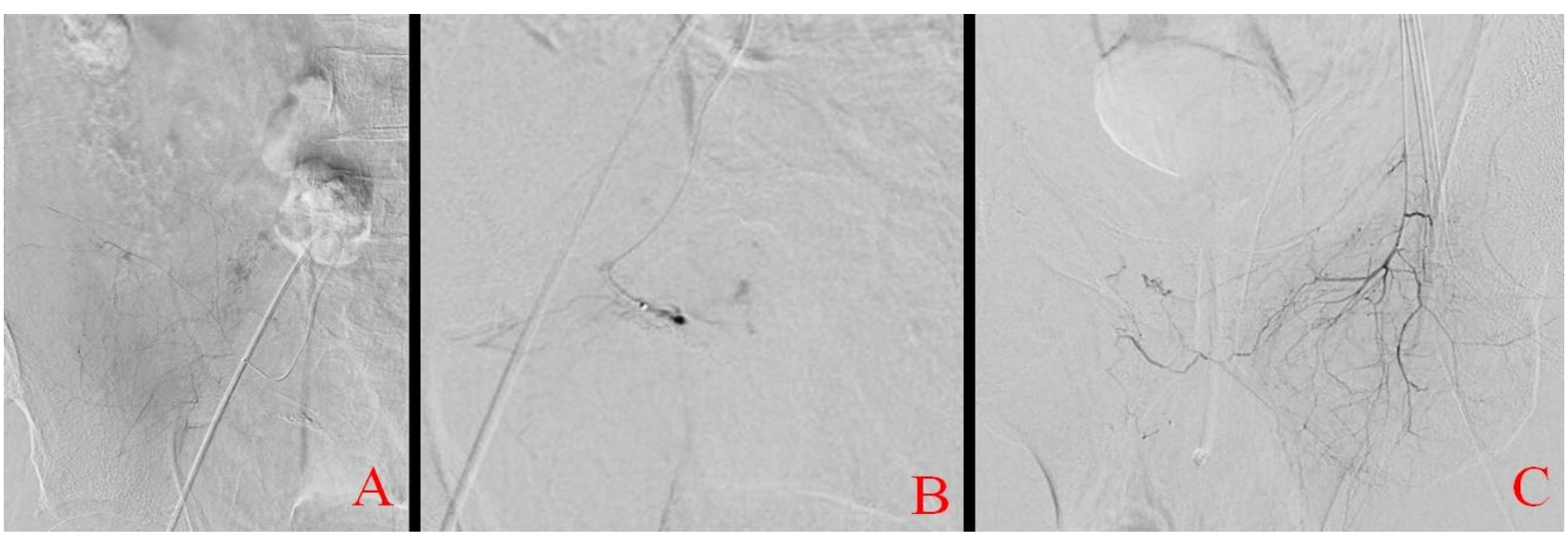

Fig. 3. Angiography showing bleeding from the right iliolumbar and both the internal pudendal arteries

Table 1. Comparison of vital signs and $A B G A$ on arrival, immediate after TAE, and 6 hours after TAE

\begin{tabular}{lccc}
\hline & On arrival & Immediate after TAE & 6 hours after TAE \\
\hline $\mathrm{BP}(\mathrm{mmHg})$ & $70 /$ & $135 / 79$ & $123 / 80$ \\
$\mathrm{HR}(/ \mathrm{min})$ & 128 & 113 & 88 \\
$\mathrm{RR}(/ \mathrm{min})$ & 40 & $18(\mathrm{MV})$ & $18(\mathrm{MV})$ \\
$\mathrm{SaO}_{2}(\%)$ & 89 & $99\left(\mathrm{FiO}_{2} 0.5\right)$ & $99\left(\mathrm{FiO}_{2} 0.5\right)$ \\
$\mathrm{BT}\left({ }^{\circ} \mathrm{C}\right)$ & 36.3 & 36.5 & 37.0 \\
$\mathrm{pH}$ & 6.99 & 7.18 & 7.38 \\
$\mathrm{HCO}_{3}^{-}(\mathrm{mM})$ & 10.8 & 16.3 & 22.5 \\
$\mathrm{Lactic}$ acid $(\mathrm{mmol} / \mathrm{L})$ & 13.5 & 7.2 & 2.1 \\
Base excess & -19.6 & -11.3 & -1.0 \\
\hline
\end{tabular}

which emphasizes the significance of the present case.

\section{Conflict of Interest Statement}

No potential conflict of interest relevant to this article was reported.

\section{REFERENCES}

1. Cheungpasitporn W, Zand L, Dillon JJ, Qian Q, Leung N. Lactate clearance and metabolic aspects of continuous high-volume hemofiltration. Clin Kidney J 2015;8(4):374-7.

2. Pannu N, Gibney RN. Renal replacement therapy in the intensive care unit. Ther Clin Risk Manag 2005;1(2): 141-50.
3. Park JY, An JN, Jhee JH, Kim DK, Oh HJ, Kim S, et al. Early initiation of continuous renal replacement therapy improves survival of elderly patients with acute kidney injury: a multicenter prospective cohort study. Crit Care 2016;20(1):260.

4. Wang H, Li L, Chu Q, Wang Y, Li Z, Zhang W, et al. Early initiation of renal replacement treatment in patients with acute kidney injury: A systematic review and meta-analysis. Medicine (Baltimore) 2016;95(46):e5434.

5. Park CY, Choi HY, You NK, Roh TH, Seo SJ, Kim SH. Continuous Renal Replacement Therapy for Acute Renal Failure in Patients with Traumatic Brain Injury. Korean J Neurotrauma 2016;12(2):89-93. 